\title{
RELAÇÕES GENÉTICAS ENTRE LATOSSOLOS E CROSTAS LATERÍTICAS ALUMI- NOSAS E ALUMINO-FERRUGINOSAS NA REGIÃO DE PARAGOMINAS, PARÁ
}

\author{
ADRIANA MARIA COIMBRA HORBE* \& MARCONDES LIMA DA COSTA**
}

\begin{abstract}
GENETIC RELATIONS BETWEEN, LATOSOLS AND ALUMINOUS AND ALUMINO-FERRUGINOUS LATERITIC CRUSTS IN THE PARAGOMINAS REGION, PARÁ Structural, textural, mineralogical and chemical datas of two lateritic profiles located in Paragominas municipality, in the NE of Pará State, are studied. The profiles with three horizons: lower, intermediate and upper that correspond, respectively to massive lateritic crust, fragmented crust and soil, are formed by the weathering of the crust in wet climate with rain forest. In these conditions the lateritic crust form the top latosol by the lost of aluminiun and iron as consequence of the dissolution of the gibbsite and hematite. The aluminium was combined with silicon fprming kaolinite that acumulated in the top of the profile forming an in situ latosol. At the same time the hematite is hidrated forming goethite giving the yellow color of the latosol.

Keywords.-laientic crust, bauxite, latosol, Belterra Clay, Amazon
\end{abstract}

RESUMO São apresentados os dados estruturais, texturais, mineralógicos e químicos de dois perfis lateríticos localizados no município de Paragominas, região NE do estado do Pará. Esses perfis, formados de três horizontes, inferior, intermediário e superior correspondentes, respectivamente, a crosta laterítica maciça, crosta laterítica fragmentada e latossolo, se formaram a partir do intemperismo da crosta em condições de clima úmido com cobertura de floresta. Sob essas condiçôes a crosta foi desaluminizada e desferruginizada de modo que a gibbsita e hematita foram dissolvidas. O alumínio liberado se recombinou com a sílica proveniente da lixiviação do quartzo e por aporte da vegetação levando a formação da caulinita que se acumulou no topo do perfil gerando o latossolo in situ. Ao mesmo tempo a hematita foi hidratada formando goethita dando a coloração amarelada ao latossolo.

Palavras chaves: crosta laterítica, bauxita, latossolos, Argila de Belterra, Amazônia

INTRODUÇÃO Os latossolos, muito abundantes na região amazônica, são argilosos a areno-argilosos avermelhados a amarelados e recobrem horizontes saprolíticos, argilosos ou crostas lateríticas. A origem desses latossolos tem sido objeto de estudos de vários pesquisadores tanto no Brasil como na África Ocidental, regiões que apresentam grande parte de seu território coberto por crostas lateríticas e latossolos. Destacam-se, na Amazónia, os trabalhos de Truckenbrodt \& Kotschoubey (1981), Lucas (1988 e 1997), Truckenbrodt et al. (1991), Lucas et al. (1993), Boulangé \& Carvalho (1997), Kotschoubey et al. (1997), Horbe \& Costa (1997 e submetido) e de Beauvais \& Mazaltarim (1988), Bilong et.al. (1992), Beauvais \&Colin (1993), Bitton \& Volkoff (1993), Beauvais \& Tardy (1993) dentre outros, na Africa.

A importância de estudar a relação entre as crostas lateríticas e os latossolos é buscar a definição da inter-relação genética entre eles que apresenta controvérsias quanto a origem, especialmente na Amazónia, podendo o latossolo estar relacionado a deposição de sedimentos lacustres, a fluxo de lama ou por degradação/intemperismo das crostas. O termo degradação é usado, especialmente, na África e Austrália, em parte devido a pouca espessura dos latossolos sugerindo mais um efeito de transformação física (Bilong et. al. 1992, Beauvais \& Colin 1993, Bitton \& Volkoff 1993, Beauvais \& Tardy 1993), enquanto que na Amazónia, eles são, em geral, mais desenvolvidos (Truckenbrodt \& Kotschoubey 1981).

Para este trabalho, que complementa o anteriormente apresentado (Horbe \& Costa 1997) foram selecionados perfis lateríticos situados na região compreendida pêlos municípios de Paragominas e Açailândia que destaca-se no cenário geológico do Pará, juntamente com a região do baixo rio Amazonas, pelas suas grandes reservas de bauxita refratária e metalúrgica. Diversos trabalhos foram desenvolvidos na região, especialmente durante a década de 70 que, além de levarem a descobertas de novas jazidas, propiciaram o estudo de detalhe sobre a lateritizacão na região (Dennen \& Norton 1977, Grubb 1979, Kronberg et al. 1979 e 1982, Hernalsteen 1982, Kotschoubey \& Truckenbrodt 1981, Truckenbrodt et al. 1982 dentre outros). Sobre a bauxita ou crosta aluminosa, assim como sobre outros tipos de crosta laterítica (sílico-ferruginosas e ferro-aluminosas) observa-se, invariavelmente, espesso pacote de latossolo argiloso amarelado com espessuras de vários metros.

Esse trabalho visa, dessa forma, apresentar dados de estruturação, texturais, mineralógicos e químicos dos latossolos e das crostas lateríticas alumino-ferruginosas e aluminosas sotopostas objetivando contribuir para o entendimento da inter-relação genética entre esses materiais. Definir a relação de autoctonia e/ou aloctónia dos latossolos em relação ao material sotoposto permitirá melhor direcionar os trabalhos de mapeamento geológico, prospeção geoquímica e o uso do solo na Amazônia.

LOCALIZAÇÃO, FISIOGRAFIA E GEOLOGIA Dois perfis localizados ao longo da BR-010 (Belém-Brasília), no município de
Paragominas, a NE do estado do Pará, foram selecionados para o presente estudo. O perfil 1 situa-se a $53 \mathrm{~km}$ a sul da sede do município e o dois na Mina de Camoaí, $19 \mathrm{~km}$ a sul do anterior (Fig. 1).

A cobertura vegetal é do tipo floresta tropical, em grande parte desmaiada, que recobre um relevo tabular, rebaixado $(50$ a $180 \mathrm{~m}$ de altitude) com vales pouco encaixados. O clima é tropical quente e úmido com índice pluviométrico de $2000 \mathrm{~mm} / \mathrm{ano}$, com uma estação seca que vai de junho a novembro e outra, úmida, no restante do ano.



Figura l-Mapa de localização dos perfis estudados. 
Os dois perfis desenvolveram-se a partir de arenitos argilosos caulínicos, conglomerados e pelitos da Formação Itapecuru, que sofreram lateritização a partir do início do Terciário, com desenvolvimento de crosta alumino-ferruginosa a aluminosa (Kotschoubey \& Truckenbrodt 1981, Truckenbrodt et al. 1982, Costa 1991, Kotschoubey et al. 1997).

MATERIAIS E MÉTODOS Somente a porção superior dos perfis, isto é, o latossolo e a crosta laterítica sotoposta foram selecionados para este estudo. Os materiais coletadas, a cada metro, apresentam duas frações granulométricas contrastantes: a- material mais grosseiro com granulação maior que $2,0 \mathrm{~cm}$ denominado de fragmento e b- material mais fino que corresponde a matriz argilosa a areno-argilosa dependendo da sua granulometria. Os fragmentos quando constituídos de nódulos envolvidos por plasma internodular são chamados de fragmentos concrecionários. Cada um desses materiais foi considerado nova amostra.

Nos fragmentos (10 amostras) e na matriz (17 amostras) foram feitas análises de difração de Raios-X e químicas para $\mathrm{SiO}_{2}$ e perda ao fogo $(\mathrm{PF})$ por gravimetria; $\mathrm{Al}_{2} \mathrm{O}_{3}$ por volumetria; $\mathrm{Fe}_{2} \mathrm{O}_{3}$ e $\mathrm{TiO}_{2}$ por colorimetria; V, Cr, B, Mo, Zr, Ga, Y, Sc e Nb (este último somente para o perfil 1) por espectrografia ótica de emissão; $\mathrm{Ni}, \mathrm{Pb}, \mathrm{Mn}$ e $\mathrm{Cu}$ por absorção atómica e ETR (somente no perfil 2) por espectometria de plasma. A interação das análises de difração de Raios-X e de óxidos maiores permitiram calcular a composição mineralógica cujos resultados são semi quantitativos. Análises de microssonda eletrônica para $\mathrm{SiO}_{2}, \mathrm{Al}_{2} \mathrm{O}_{3}$ e $\mathrm{Fe}_{2} \mathrm{O}_{3}$ restringiram-se aos fragmentos da crosta do perfil 2. Foram realizadas análises de microscopia eletrônica de varredura (MEV) com espectrômetro de energia dispersiva (EDS) acoplado e de microssonda eletrônica visando os aspectos micromorfológicos, microtexturais e químicos.

PERFIL 1 - LATOSSOLO SOBRE CROSTA ALUMINOFERRUGINOSA Estruturação do perfil E possível diferenciar três horizontes da base para o topo do perfil (Fig. 2):

Horizonte Inferior: constituído pela crosta alumino-ferruginosa maciça com matriz argilosa preenchendo fissuras e fraturas. Apresenta, em média, 3,6 $m$ de espessura.

Horizonte Intermediário: constituído por fragmentos centimétricos, isolados, de estrutura concrecionária. Apresentam composição alumino-ferruginosa e subordinadamente ferruginosa, estando envolvidos por matriz argilosa avermelhada. Espessura média de $1,0 \mathrm{~m}$.

Horizonte Superior ou Latossolo: constituído por matriz argilosa com raros nódulos milimétricos alumino-ferruginosos e ferruginosos amarelados e avermelhados dispersos e discordantes. É muito homogéneo, sem estruturação visível, de coloração avermelhada tendendo a ocre e microagregada no topo. Apresenta espessura máxima de $13,8 \mathrm{~m}$

Aspectos texturais da crosta e fragmentos A crosta do horizonte inferior é texturalmente heterogénea, sendo formada por porções compactas, maciças a porosas, às vezes cavernosas, de col- oração rosada a avermelhada. Ocorrem, localmente, porções marrons ferruginizadas com formas ovóides a arredondadas sugerindo segregação. É correlacionável as crostas definidas como maciças por Tardy (1993).

Os fragmentos concrecionários do horizonte intermediário são constituídos por dois tipos de materiais: a) concreções ferruginosas, isoladas, com até $2 \mathrm{~cm}$ de diâmetro, zonadas, com núcleo hematítico avermelhado e poroso e córtex, com 1 a $2 \mathrm{~mm}$ de espessura, de material goethítico marrom escuro; b) concreções com até $5 \mathrm{~cm}$ de diâmetro formadas por nódulos ferruginosos e aluminosos rosados, envolvidos por plasma internodular amarelo a creme de composição gibbsítica (Fig. 3). A concreção b, que pode ser correlacionada com as crostas pisolíticas e nodulares de Tardy (1993), apresenta os contatos dos nódulos com o plasma internodular difusos sugerindo um processo de desferrificação. A porção ferruginosa desta concreção é, provavelmente, a fonte da concreção a.

Análises de microscópio eletrônico da crosta e do plasma internodular mostram que são constituídos de gibbsita micro (com cristais bem formados) a criptocristalina sendo esta última a que predomina, especialmente no plasma internodular, enquanto a microcristalina está restrita a pequenas cavidades (Fig. $4 \mathrm{~A} \mathrm{e} \mathrm{B}$ ). Na gibbsita microcristalina é possível observar a forma hexagonal dos seus cristais e bordas de corrosão (Fig.4 B e C).

No horizonte inferior ocorre, preenchendo fraturas, fissuras e poros, uma matriz argilosa avermelhada que passa a envolver totalmente os

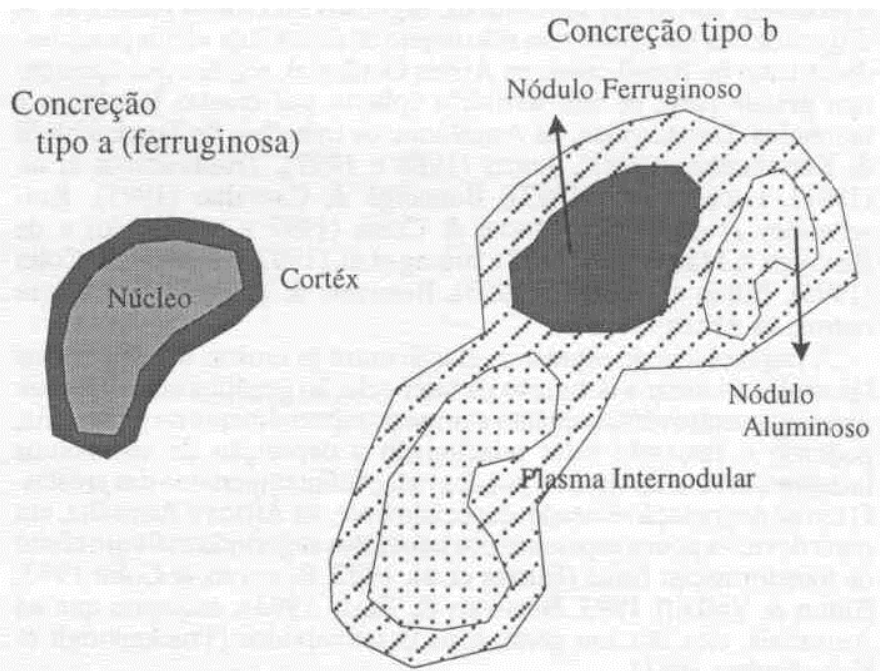

Figura 3 - Desenho esquemático das concreções tipo a eb encontradas no horizonte intermediário do perfil 1.

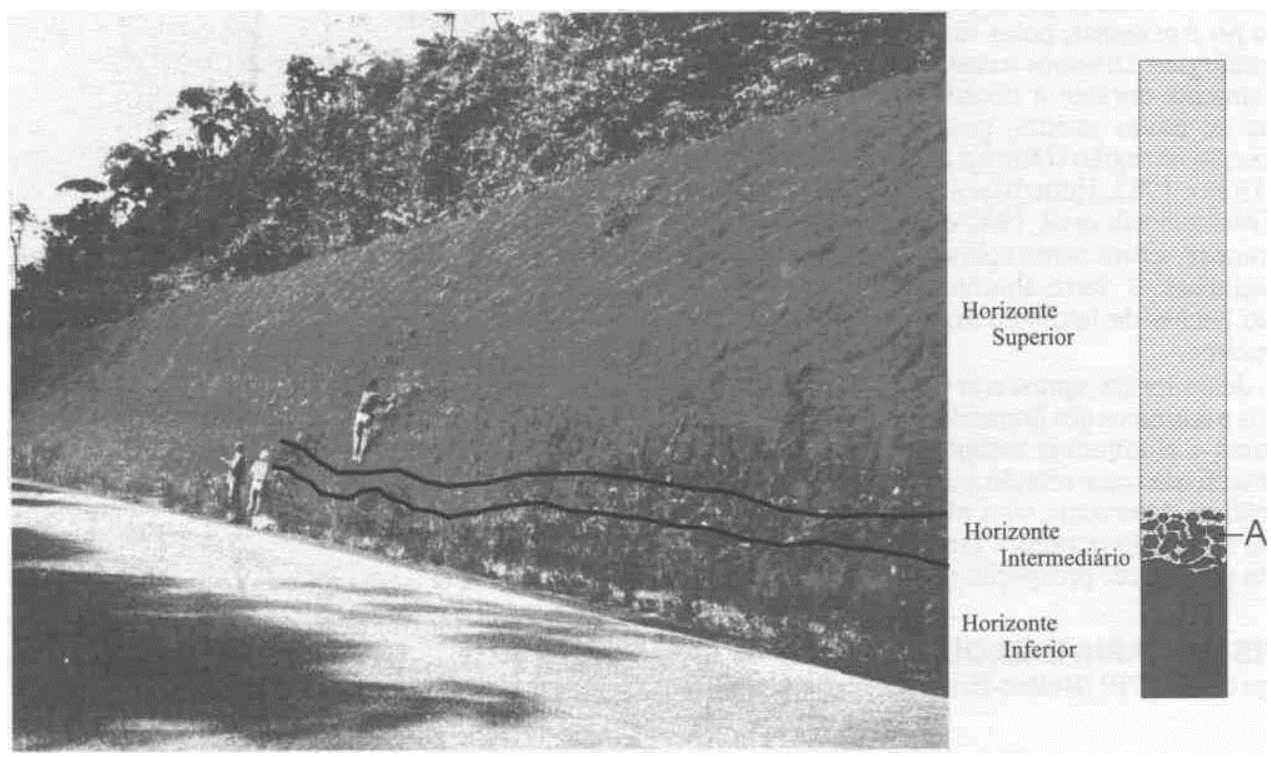

Figura 2 - Aspecto do perfil l desenvolvido sobre crosta laterítica alumino-ferruginosa (A-fragmentos). 


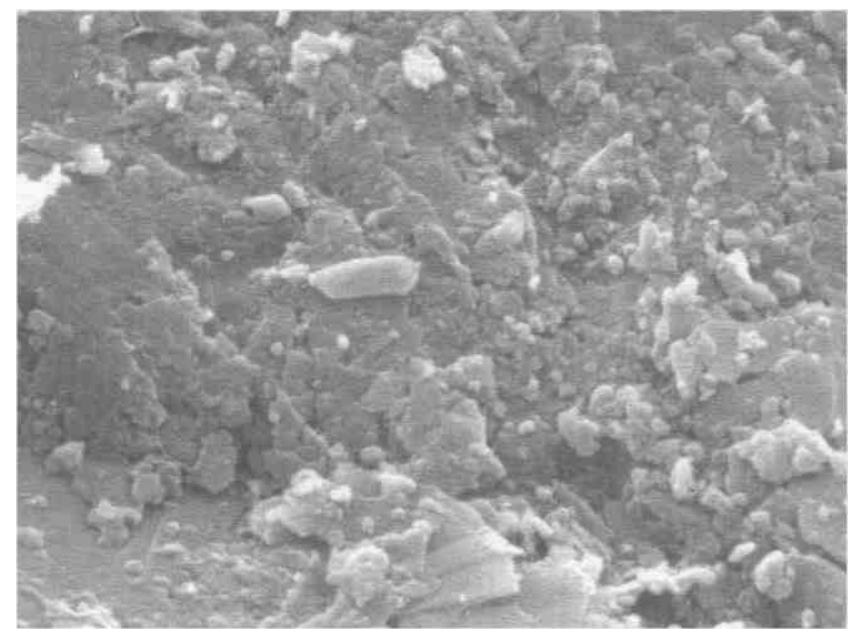

A- $7000 x$



\section{C- $2000 x$}

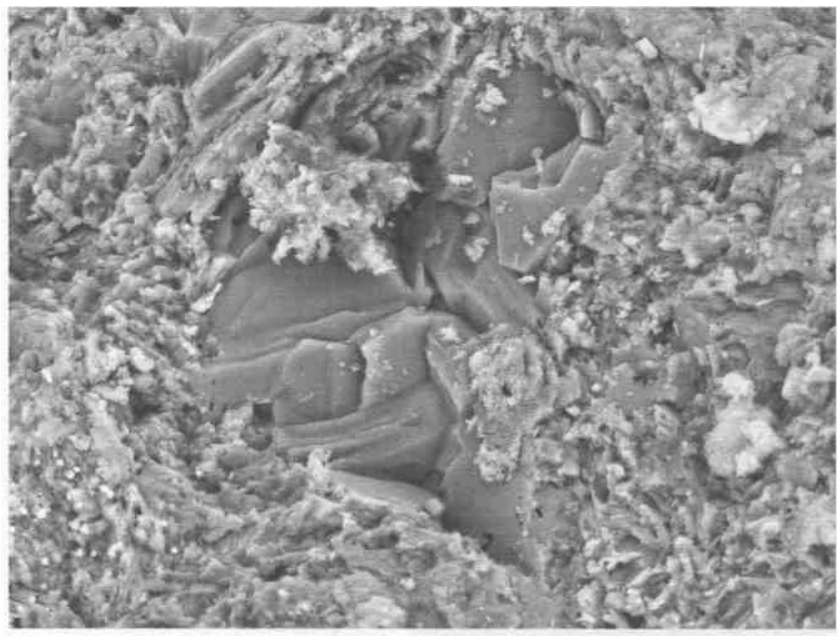

E- 665x

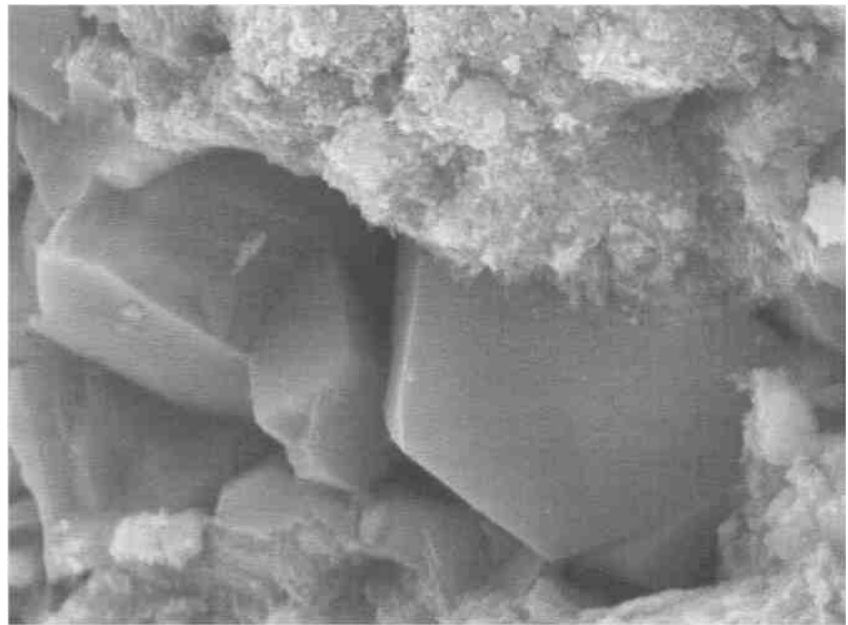

B- $4000 x$

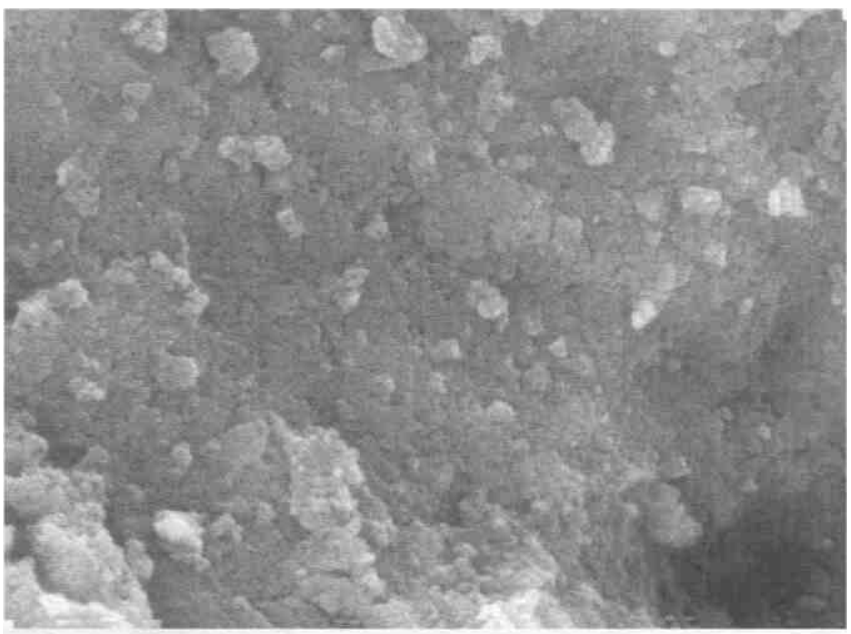

D- $10000 x$

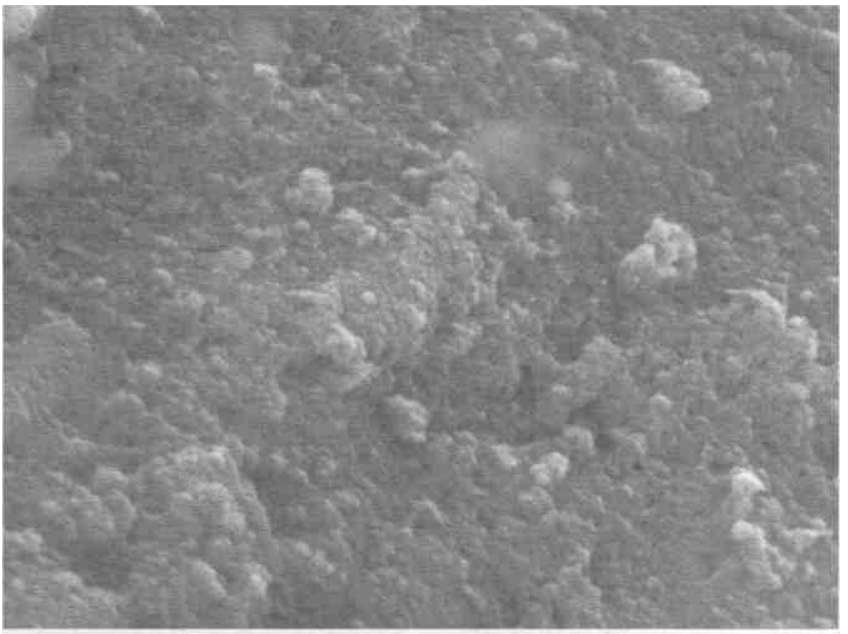

F- $1240 x$

Figura 4 - Fotografias de microscópio eletrônico de varredura do perfil 1: A- textura criptocristalina típica da crosta alumino-ferruginosa e do plasma internodular; $B$ e $C$ - aspecto dos cristais de gibbsita que ocorrem nos poros e de sua corrosão (parte superior da figura C); $D$ Textura criptocristalina da matriz argilosa; e do perfil 2: E- textura micro cristalina e D-criptocristalina da gibbsita que constitui a crosta aluminosa do perfil 2. 
fragmentos no horizonte intermediário e predomina no superior. A Fig. 4 D mostra que essa matriz é texturalmente criptocristalina. Composição mineralógica A crosta é formada, basicamente, por gibbsita e caulinita com predomínio da primeira (Tab. 1). Hematita, goethita, anatásio e quartzo ocorrem muito subordinadamente sendo que este último em uma única amostra da crosta. A amostra representativa da porção mais ferruginosa apresenta $75 \%$ de hematita + goethita e, consequentemente, menos gibbsita e caulinita. A presença de porções com predomínio de hematita e goethita na crosta gibbsítica a caracteriza como alumino-ferruginosa.

Os fragmentos apresentam composição mineralógica variável predominando ora a gibbsita ora a hematita + goethita, ocorrendo quartzo em somente uma amostra (Tab. 1).

A matriz argilosa dos horizontes inferior e intermediário é, basicamente, caulinítica com gibbsita e hematita + goethita subordinados e menos de $2 \%$ de anatásio (Tab. 1).
O horizonte superior é mais caulinítico em relação a matriz argilosa dos horizontes inferiores e, consequentemente, menos gibbsítico (Tab. 1). Em direção ao topo, essa tendência se acentua, exceto a $10 \mathrm{~cm}$ da superfície onde gibbsita e quartzo, com $35 \%$ cada um são os constituintes principais devido, provavelmente, a enriquecimento residual desses minerais (Tab. 1). Quartzo ocorre em quase todas as demais amostras (com teores de até 10\%).

Composição química $\mathrm{O}$ horizonte inferior caracteriza-se pelos teores elevados de $\mathrm{Al}_{2} \mathrm{O}_{3}$ e $\mathrm{PF}$ (porção aluminosa) ou de $\mathrm{Fe}_{2} \mathrm{O}_{3}$ (porção ferruginosa) enquanto os de $\mathrm{SiO}_{2}$ e $\mathrm{TiO}_{2}$ são mais baixos (Fig. 5) refletindo o predomínio de gibbsita ou hematita + goethita, respectivamente. Esse mesmo padrão, também, é observado nos fragmentos do horizonte intermediário.

Na matriz argilosa dos três horizontes as curvas de distribuição são similares entre si com predomínio de $\mathrm{Al}_{2} \mathrm{O}_{3}$ e $\mathrm{SiO}_{2}$ (Fig. 5) caracterizando a presença mais abundante de caulinita e quartzo (Tab. 1). No horizonte superior há a tendência dos teores de $\mathrm{SiO}_{2}$ aumentarem para


Figura 5 - Composição química do perfil 1.
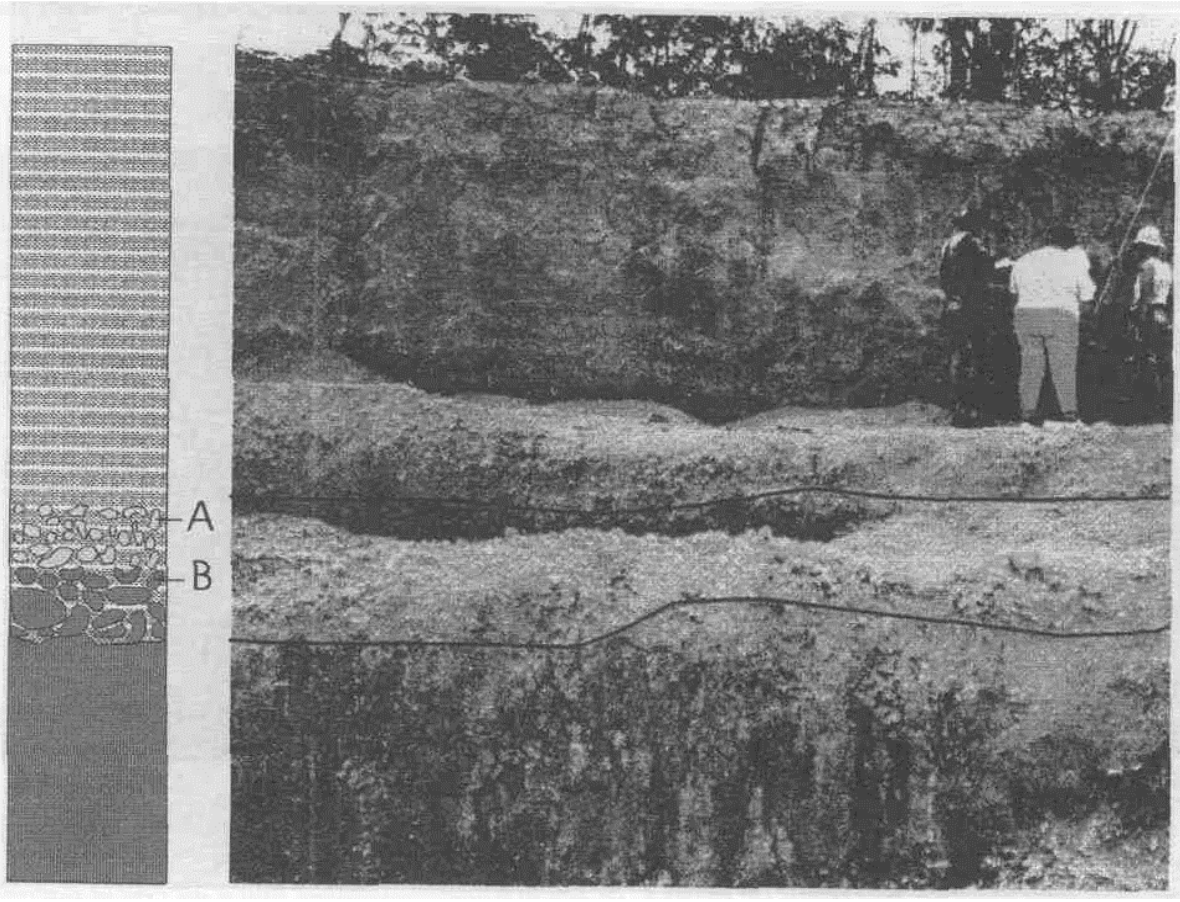

\section{Horizonte}

Superior

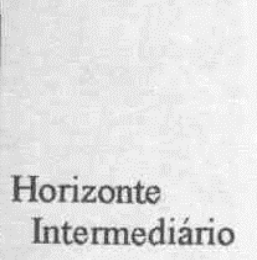

Horizonte

Inferior

Figura 6 - Aspecto do perfil 2 desenvolvido sobre crosta laterítica aluminosa (A-concreções do topo do horizonte intermediário e B-fragmentos da base desse mesmo horizonte). 
o topo do perfil, em detrimento de $\mathrm{Al}_{2} \mathrm{O}_{3}$, devido ao maior acúmulo de quartzo, de modo que a razão $\mathrm{SiO}_{2} / \mathrm{Al}_{2} \mathrm{O}_{3}$, que está entre 0,74 e 0,89 na matriz argilosa do horizonte inferior, alcança até 1,45 no topo do perfil.

Análises químicas semi-quantitativas obtidas por MEV/EDS mostram que a gibbsita criptocristalina da crosta e dos fragmentos tende a apresentar teores elevados de $\mathrm{SiO}_{2}(10 \%$ a $36 \%)$ e $\mathrm{Fe}_{2} \mathrm{O}_{3}(6 \%$ a $26 \%$ ), quando comparada com a microcristalina, cuja composição é, praticamente, só $\mathrm{Al}_{2} \mathrm{O}_{3}(92 \%$ a $97 \%)$.

Tabela, l- Composição mineralógica, em peso, dos perfis estudados.

\begin{tabular}{|c|c|c|c|c|c|}
\hline \multicolumn{6}{|c|}{ Perfil I - sabre crosia aluminosa } \\
\hline Horizonles & Quartion & Caulinita & Gibhsita & Hem+Goe & Anatísio \\
\hline \multicolumn{6}{|c|}{ Horizonue Superior } \\
\hline M. Argilosa & 35 & 22 & 35 & 8 & $i$ \\
\hline & 5 & 69 & 96 & .9 & $i$ \\
\hline & (16) & 78 & 1 & 8 & i \\
\hline & 10) & 78 & 1 & 8 & 2 \\
\hline & 1 & 71 & 18. & 9 & $\leqslant 1$ \\
\hline & + & 83 & 4 & 9 & 1 \\
\hline & 5 & 59 & 26 & 9 & 1 \\
\hline & ${ }^{\circ}$ & 71 & 19 & 9 & $\mathbf{I}$ \\
\hline \multicolumn{6}{|c|}{ Hiprizonte Intermedifirio } \\
\hline M. Argillosa & + & 65 & 21 & 10 & 1 \\
\hline Fragmenio & 5 & 10 & 74 & 8 & 2 \\
\hline M. Argilasa & - & 65 & 21 & 14 & T \\
\hline Fragmeno & & 13 & 77 & 6 & 3 \\
\hline Fragmento & & 25 & 24 & 45 & $\overline{2}$ \\
\hline \multicolumn{6}{|c|}{ Horizomie Inferior } \\
\hline M. Argitosa & . & $\overline{73}$ & 14 & 12 & 1 \\
\hline M. Argilasa & - & 56 & 13 & 27 & 2 \\
\hline M. Argilasa & - & 60 & 21 & 16 & 1 \\
\hline Crosta & . & 43 & 47 & 4 & 2 \\
\hline Crosta & - & 13 & 82 & 1 & $\overline{2}$ \\
\hline Crosta & $\cdot$ & 12 & 7 & 75 & ] \\
\hline Crosta & 7 & 2 & 84 & 5 & 2 \\
\hline
\end{tabular}

\begin{tabular}{|c|c|c|c|c|c|}
\hline \multicolumn{6}{|c|}{ Pernil 2 - sobre crosta aluminosa } \\
\hline Horizonles & Quartzo & Caulinitas & Glbosita & Hem+Goe & Allallisio \\
\hline \multicolumn{6}{|c|}{ Horizance Superior } \\
\hline M. Argilosa & 10 & 73 & 12 & 3 & 1 \\
\hline & 9 & 72 & 14 & 3 & 2 \\
\hline \multirow{2}{*}{\multicolumn{6}{|c|}{ 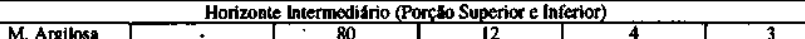 }} \\
\hline M. Argilos: & & & & & 3 \\
\hline Fragmemo & $\dot{\circ}$ & 13 & 78 & 6 & 2 \\
\hline M. Argilosa & $=$ & 85 & 10 & $\sqrt{3}$ & 1 \\
\hline Fragmento & 1 & 32 & 64 & 2 & 1 \\
\hline \multirow{2}{*}{\multicolumn{6}{|c|}{$\begin{array}{l}\text { Horizonte Infarior } \\
13\end{array}$}} \\
\hline & & & & I & $T$ \\
\hline
\end{tabular}

Os elementos-trace caracterizam-se pelas suas baixas concentrações, exceto o $\mathrm{Zr}$ (Fig. 5), em consequencia da origem do material ser, basicamente, a partir de sedimentos areno-argilosos, normalmente, pobres nesses elementos. Há tendência dos teores de $\mathrm{Zr}$ serem mais elevados na matriz argilosa, enquanto, os de $\mathrm{V}$ e Cr predominam no horizonte inferior e nas concreções do horizonte intermediário, o primeiro associado, provavelmente, ao zircão e os demais aos óxihidróxidos de ferro. Essa tendência de distribuição do V, Cr e $\mathrm{Zr}$ ao longo do perfil, também, foi observada em perfis similares (Boulangé \& Carvalho 1997 e Horbe \& Costa 1997).

PERFIL 2 - LATOSSOLO SOBRE CROSTA ALUMINOSA Estruturação do perfil Este perfil é constituído por três horizontes da base para o topo (Fig. 6):

Horizonte inferior - formado por crosta aluminosa, com espessura aflorante de $0,50 \mathrm{~m}$ (não se observa o contato inferior), textura colunar e macica formando blocos métricos. Apresenta fraturas e fissuras preenchidas por material argiloso amarelado a levemente rosado.

Horizonte intermediário - $E$ constituído, na base, por fragmentos decimétricos similares ao horizonte inferior, e no topo por concreções centimétricas. Ambos apresentam-se envolvidos por abundante matriz argilosa. Apresenta espessura média de $0,30 \mathrm{~m}$.

Horizonte superior ou latossolo - É formado por matriz argilosa amarelada com 2,0 m de espessura média, sem estruturação visível, contendo fragmentos nodulares, milimétricos, amarelados, esparsos e discordantes, similares aos encontrados nos horizontes inferiores.

Aspectos texturais da crosta e fragmentos A crosta do horizonte inferior e os fragmentos da base do horizonte intermediário apresentam duas fácies interdigitadas ambas constituídas por gibbsita: 1- rosada a levemente avermelhada predominante e 2-amarelada a creme. A observação ao MEV mostra que a gibbsita da fácies rosada é cripto a microcristalina, sendo a primeira mais abundante e a microcristalina restrita aos seus poros (Fig. 4 E). A gibbsita da fácies amarelada, também chamada de fácies porcelanada, é essencialmente criptocristalina (Fig. 4 F). Microesferas de hematita dispersas na superficie da gibbsita dão a cor rosada a fácies 1 .

Os fragmentos concrecionários do topo do horizonte intermediário, com menos de $3 \mathrm{~cm}$ na maior dimensão, apresentam formas irregulares sugerindo dissolução. São constituídos por dois tipos de nódulos com até $1 \mathrm{~cm}$ de diâmetro: a) ferruginoso de cor marrom avermelhada formado por grande concentração de micro-esferas de hematita semel-
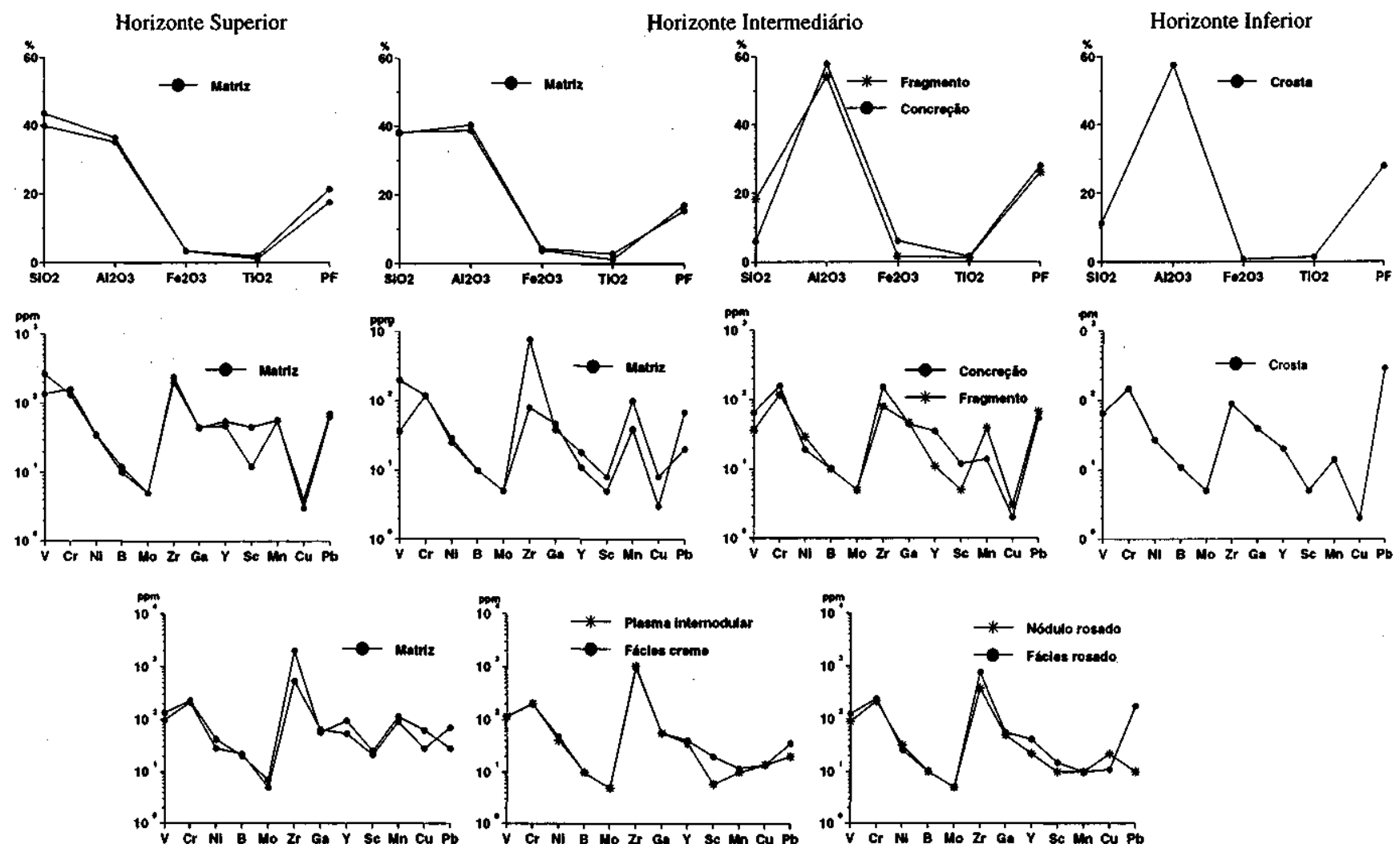

Figura 7 - Composição química do perfil 2. 
hantes as encontradas na fácies rosada e b) similar a fácies rosada do horizonte inferior. Os dois tipos de nódulos estão envolvidos por plasma internodular gibbsítico semelhante a fácies amarelada do horizonte inferior. $\mathrm{O}$ contato entre os nódulos e o plasma internodular é difuso sugerindo passagem gradual.

Os fragmentos concrecionários são correlacionáveis a crosta pisolítica, enquanto, o horizonte inferior à crosta maciça segundo a classificação de Tardy (1993).

Composição mineralógica Caulinita e gibbsita compõem quase $90 \%$ da composição mineralógica do perfil (Tab. 1). A gibbsita é o mineral principal no horizonte inferior e nos fragmentos do intermediário enquanto a caulinita predomina na matriz argilosa. Os demais minerais são quartzo, hematita, goethita e anatásio. O quartzo apresenta teores crescentes na matriz argilosa alcançando $10 \%$ a 10 $\mathrm{cm}$ do topo do perfil e a hematita e goethita predominam nos fragmentos concrecionários da porção superior do horizonte intermediário $(6 \%)$. O anatásio apresenta-se entre $1 \%$ e $3 \%$.

Composição química $\mathrm{SiO}_{2}, \mathrm{Al}_{2} \mathrm{O}_{3}$ e $\mathrm{PF}$ são os principais constituintes do perfil (Fig. 7) relacionados, essencialmente, a caulinita e gibbsita. Os teores de $\mathrm{Al}_{2} \mathrm{O}_{3}$ e $\mathrm{PF}$ são mais elevados no horizonte inferior e nos fragmentos do intermediário, enquanto, $\mathrm{Fe}_{2} \mathrm{O}_{3}$ e $\mathrm{TiO}_{2}$ são os mais baixos.

A matriz argilosa apresenta-se bastante homogénea ao longo do perfil, com teores mais elevados de $\mathrm{SiO}_{2}$ e $\mathrm{Al}_{2} \mathrm{O}_{3}$ (Fig. 7) devido a presença de quartzo, caulinita, e gibbsita. As razões $\mathrm{SiO}_{2} / \mathrm{Al}_{2} \mathrm{O}_{3}$, entre 0,20 , no horizonte inferior, e próximo de 1 no topo, reforçam o predomínio de gibbsita na base e de caulinita e quartzo no topo. $\mathrm{TiO}_{2}$ varia entre $1 \%$ e 3\% não havendo tendência de diferenciação ao longo do perfil.

As análises por microssonda nos fragmentos da crosta indicam para a fácies rosada teores constantes de $65 \%$ de $\mathrm{Al}_{2} \mathrm{O}_{3}$ que corresponde a quase $100 \%$ de gibbsita, enquanto a fácies amarelada apresenta entre $46 \%$ e $60 \%$ mostrando que, além de gibbsita ocorre caulinita nessa fácies. Esse aspecto e a textura criptocristalina, sugerem que a fácies amarelada pode estar representando uma fase intermediária entre a rosada, predominante no horizonte inferior, e a matriz argilosa, conforme observado por Black et al. (1984), Bardossy \& Aleva (1990) e Lucas (1997) em outros perfis.

Os teores dos elementos-traço são baixos no perfil, por já se encontrarem, originalmente, empobrecidos na rocha mãe como foi também, observado no perfil 1 .
O padrão de distribuição dos elementos-traço é marcado pelos teores mais elevados de V, $\mathrm{Cr}$ e $\mathrm{Zr}$ e, secundariamente, $\mathrm{Mn}$ e $\mathrm{Pb}$ que diferenciam-se dos demais elementos com baixa concentração $(<50$ ppm) (Fig. 7). Há tendência do $\mathrm{Zr}$ apresentar maiores concentrações para o topo do perfil, mas em proporção menor que no perfil 1. Nas fácies rosada e amarela da crosta, nos nódulos e no plasma internodular das concreções e na matriz argilosa que preenche os poros desses materiais, o padrão de distribuição é o mesmo dos fragmentos e da matriz argilosa como um todo (Fig. 7) mas com concentrações um pouco mais elevadas.

Os elementos terras raras (ETR), analisados somente nos fragmentos e na matriz argilosa, apresentam concentrações um pouco acima da média crustal e mostram predomínio do $\mathrm{La}$, Ce e $\mathrm{Nd}$ sobre os demais elementos (Tab. 2). Os fragmentos da base do horizonte intermediário apresentam os teores mais altos $(\Sigma \mathrm{ETR}=127,18 \mathrm{ppm})$ que os do topo desse mesmo horizonte $(\Sigma \mathrm{ETR}=62,89 \mathrm{ppm})$. A matriz argilosa apresenta concentrações mais elevadas que os fragmentos $(\Sigma \mathrm{ETR}=$ $170,02 \mathrm{ppm})$ com tendência a decrescerem para o topo $(\Sigma \mathrm{ETR}=93,15$ ppm). Apresentam-se pouco fracionados com a relação $\mathrm{La}_{\mathrm{N}} / \mathrm{Yb}_{\mathrm{N}}$, entre 5,00 e 11,15, não havendo distinção nesse parâmetro entre fragmentos e matriz. As curvas de normalização em relação aos condritos mostram-se similares ao longo do perfil com pequena anomalia negativa em Eu (Fig. 8).

DISCUSSÕES E CONCLUSÕES Comparando os dois perfis estudados observa-se que ambos tem características estruturais e texturais similares. A estruturação mostra aumento crescente no grau de desagregação marcada pela fragmentação da crosta, pela presença de material concrecionário no horizonte intermediário e a quase total cominuição dos fragmentos no horizonte superior em um típico processo granodecrescente. Esses aspectos, reforçados pelos texturais, como a presença de crosta maciça na base e pisolítica a nodular na porção intermediária, o contato difuso entre os nódulos e o plasma internodular dos fragmentos, além da corrosão nos cristais de gibbsita, sugere desaluminização e desferrificação. Como consequência tem-se a individualização de fragmentos cada vez menores em direção ao topo do perfil em um processo de desagregação associado a concrecionamento de modo similar ao observado em outros perfis na Amazônia (Horbe \& Costa 1997). Essas modificações na estrutura e textura dos horizontes inferiores para os superiores pode ser correlacionada ao que se observa no intemperismo de rochas primárias de modo que a crosta representa a rocha-mãe do perfil e o solo o produto de seu intemperismo. A presença de fragmentos concrecionários nos horizontes inter-

Tabela 2 - Concentração dos elementos terras raras, em ppm no perfil 2.

\begin{tabular}{|l|c|c|c|c|c|c|c|c|c|c|c|}
\hline Horizontes & La & Ce & Nd & Sm & Eu & Gd & Dy & Ho & Er & Yb & La \\
\hline M Argilosa & 23,45 & 45,21 & 15,80 & 1,48 & 0,31 & 1,49 & 2,07 & 0,44 & 1,29 & 1,42 & 0,19 \\
\hline M Argilosa & 35,63 & 67,17 & 28,37 & 2,47 & 0,47 & 2,24 & 3,21 & 0,70 & 2,15 & 2,36 & 0,33 \\
\hline \multicolumn{8}{|c|}{ Horizonte Intermediário (Porção Superior e Inferior) } \\
\hline M Argilosa & 42,42 & 68,83 & 35,01 & 2,75 & 0,50 & 2,85 & 5,38 & 1,28 & 4,43 & 5,73 & 0,84 \\
\hline Fragmento & 14,82 & 26,35 & 13,65 & 1,09 & 0,21 & 0,82 & 1,78 & 0,44 & 1,58 & 1,89 & 0,26 \\
\hline M Argilosa & 39,94 & 60,84 & 12,06 & 2,18 & 0,44 & 2,47 & 3,67 & 0,83 & 2,69 & 3,32 & 0,47 \\
\hline Fragmento & 46,84 & 52,46 & 13,56 & 2,16 & 0,39 & 2,04 & 2,94 & 0,69 & 2,51 & 3,13 & 0,46 \\
\hline
\end{tabular}

\section{Horizonte Superior}

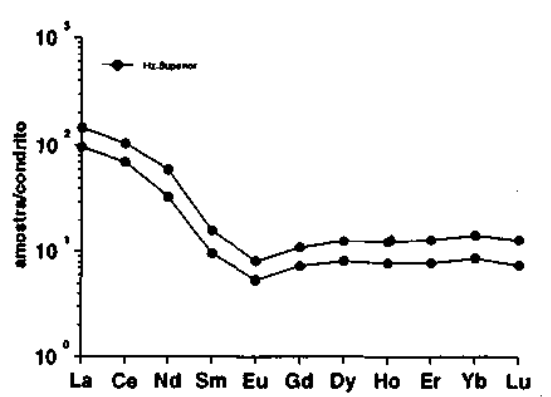

\section{Horizonte Intermediário}

\section{Porçāo Superior Porção Inferior}
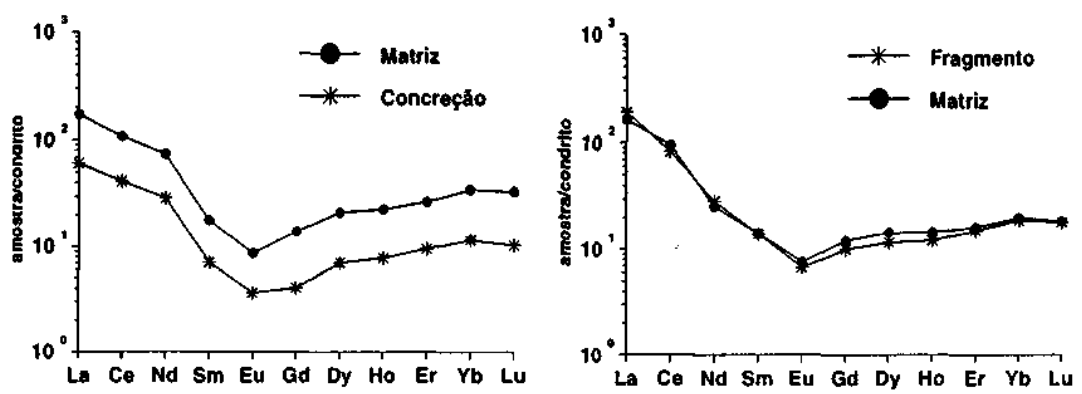

Figura 8 - Curvas de fracionamento dos elementos terras raras no perfil 2. 


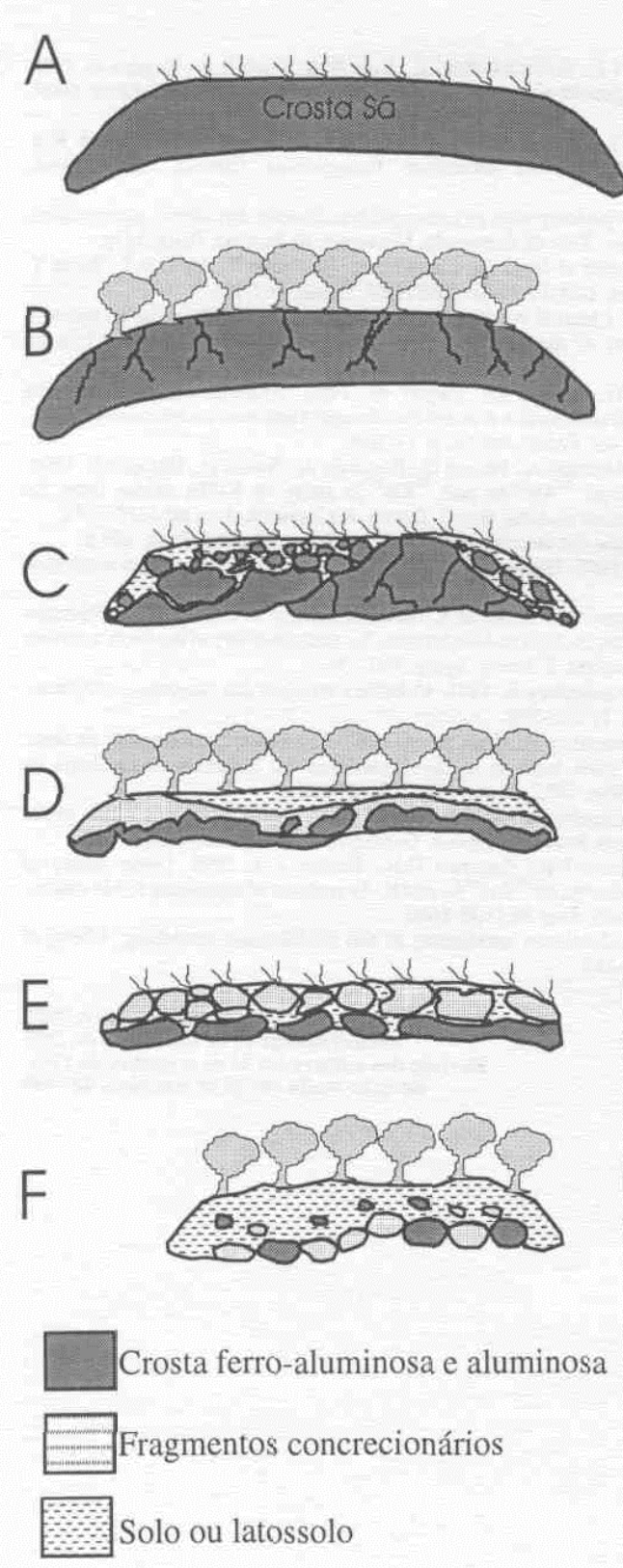

Figura 9 - Esquema evolutivo dos solos a partir de crostas lateríticas segundo o tempo geológico.

mediários, similares textural, mineralógica e quimicamente à crosta, corrobora essa possibilidade.

O plasma internodular das concreções com textura predominante (perfil 1) a exclusivamente criptocristalina (perfil 2) sugere que ele poderia ser a fase intermediária entre a gibbsita microcristalina e a matriz argilosa caulinítica-gibbsítica criptocristalina do topo. Essa possibilidade é enfatizada pela corrosão observada nas bordas dos cristais de gibbsita e pelas análises de MEV e microssonda na qual a fácies amarela e o plasma internodular tendem a serem criptocristalinos e mais silicosos que o rosado. Além disso é marcante o processo de desferrificação que se observa entre a fáceis rosada e a amarela da crosta e entre os nódulos e o plasma internodular das concreções, assemelhando-se a transformação das crostas ferruginosas marromavermelhadas para ocres por degradação, segundo Beauvais \& Mazaltarim (1988), Tardy, (1993) entre outros. O próprio aspecto concrecionário dos fragmentos e a presença de nódulos milimétricos de gibbsita amarelada no horizonte superior são evidências da transformação sofrida pela crosta.

Além da estrutura e textura, a composição mineralógica sugere correlação entre os materiais dos perfis, especialmente no perfil l, onde as matrizes argilosas dos horizontes inferiores e intermediários são, em média, mais gibbsíticas e hematíticas-goethíticas, compatíveis com a composição das crostas e fragmentos aos quais estão associadas, tornando-se gradativamente mais caolinítica e quartzosa no horizonte superior. Essa modificação mineralógica é correlacionável com o observado por Lucas (1997) em perfis similares na Amazónia. A neoformação de caulinita e a sua acumulação em direção ao topo do perfil é um processo típico da degradação de crostas lateríticas tanto aluminosas como ferruginosas (Muller et al. 1980) levando, no caso dos dois perfis e em outros similares (Horbe \& Costa 1997), a, concomitante, acumulação de quartzo e gibbsita. A variação mineralógica na matriz argilosa ao longo do perfil, apoiada pela composição química, demonstra a sua compatibilidade genética com a crosta e os fragmentos.

A tendência de transformação de gibbsita em caulinita estaria relacionada a posição do lençol freático e, consequentemente, a atividade da água (Tardy et al. 1990). Assim, a gibbsita tende a se formar onde a atividade da água é maior, enquanto a caulinita, com menor teor de água, se forma acima do lençol freático. Segundo Wesselink (1990) nos solos a gibbsita está em equilíbrio em subsuperfície, enquanto, a subsaturação em água da superficie é mais apropriada para a formação de caulinita. A sílica necessária para a transformação da gibbsita em caulinita seria fornecida, predominantemente, pela dissolução do quartzo, que está, constantemente presente, também em outros perfis estudados (Truckenbrodt et al. 1991, Boulangé \& Carvalho 1997, Lucas 1997, Horbe \& Costa 1997) e/ou pelo aporte pela vegetação (Lucas et al. 1993). A ausência de horizonte gibbsítico em perfis formados a partir do Quaternário (Costa 1991, Fernandes Filho et al. 1996 e Horbe \& Costa 1997) e a larga distribuição da caulinita nos solos da região reforça a incompatibilidade desses dois minerais no clima atual.

A possibilidade de filiação geoquímica entre crosta e matriz é ressaltada pelo padrão similar de distribuição dos elementos-traço e ETR. Os elementos-traço com concentraç̃es bastante similares entre os materiais e ao longo do perfil, e afinidades naturais com a fase ferruginosa (V, Cr, Ni, Mn, Cu e Pb), aluminosa (Ga, Sc e Y) e residual $(\mathrm{Zr}, \mathrm{B}$ e $\mathrm{Nb}$ ), sugerem que o material que gerou os horizontes de cada perfil é um só e compatível com o processo intempérico de crostas lateríticas aliado a pedogênese e esculpimento da paisagem.

Considerando que a rocha-mãe dos perfis estudados (Formação Itapecuru) foi depositada no Cretáceo (Góes \& Feijó 1994) e que o início da lateritização na Amazónia deu-se entre o Cretáceo Superior e o Paleoceno (Vasconcellos et al. 1994 e Ruffet et al. 1996) com o máximo no Oligoceno (Tardy \& Roquin 1998), a crosta laterítica dos perfis estudados já estaria individualizada no final desse período. A partir da individualização das crostas lateríticas e com a alternância, em intervalos de tempo cada vez menores, entre o clima mais úmido e mais seco e quente, especialmente, nos períodos glaciais-interglaciais do Quaternário, é possível esquematizar a sequência de transformação das crostas em solos em seis estágios (Fig. 9). A, C e E representam as etapas de clima mais seco com desenvolvimento de vegetação tipo caatinga/savana e B, D e F de clima mais úmido com cobertura de floresta. Nos estágios mais secos a fraca cobertura vegetal propicia o processo erosivo removendo a parte superior do perfil que se acumula nas encostas e porções rebaixadas do relevo expondo a crosta aluminosa e ao mesmo tempo, levando a maior ferruginização do perfil. Nos estágios B, D e F a crosta passa a sofrer influência da vegetação e da menor disponibilidade de água, pois está acima do lencol freático, de modo que a gibbsita é ressilicificada e a hematita se hidrata formando, respectivamente, caulinita e goethita e originando o solo. Desse modo os solos sobrepostos a crostas e fragmentos lateríticos seriam resultantes do intemperismo em clima úmido e as grandes espessuras de solo podem estar associados a movimentos de massa sucessivos nos períodos de clima mais seco.

Agradecimentos Ao $\mathrm{CNPq}$ pela bolsa de doutorado ao primeiro autor e de pesquisador ao segundo. Aos Profs. António Rossi e Gian Paolo Signolffi pela oportunidade de utilização do microscópio eletrônico de varredura na Universita Degli Studi di Modena, Itália. Finalmente, ao Pró f. Rômulo S. Angélica pelos comentários e sugestões ao texto. 
Bardossy G. \& Aleva G.J.J. (1990) Laterinc bauxites. Developments in Economic Geology, .27. Amsterdam, Elsevier. 624p.

Beauvais A. \& Mazaltarin D. 1988. Étude des cuirasses latéritique dans Ia region de Dembia-Zémio en Centrafrique. Pétrographie, minéralogie et géochimie. Sei. Géol., Bull., 41: 47-69

Beauvais A. \& Colin F. 1993. Formation and tranformation processes of iron duricrust systems in tropical humid environment. Chem. Geoi, 106:77-101.

Beauvais A. \& Tardy Y. 1993. Degradation and dismantling of iron crust under climatic changes in Central Africa Chem. Geol., 107:277-288.

Bilon P., Belinga S.E., Volkoff B. 1992. Séquence d'évolution des paysages cuirasses et des sois ferrallitiques en zone forestières tropicales d'Afrique central. Place des sois à horizons d'argile tachatée. C. R. Acad. Sei. Paris 314:109-115.

Bitton D. \& Volkoff B. 1993. Alteration déferruginisante des cuirasses massives et formation des horizons gravillionares ferrugineux dans les sois de l'Afrique Central humide. C.R. Acad.Sci., 316:1447-1454

Black R.Y., Lozej G.P. Maddah S.S. 1994. Geology and mineralogy of the Zabirah bauxite, northern Saudi Arábia. In: Jacob, Jr., L. (ed.) Baixites. New York, Society of Mining Engineers. p.619-638.

Boulange B. \& Carvalho A. 1997. The bauxite of Porto Trombetas. In: Carvalho A., Boulangé B., Melfi A. J. \& Lucas Y. (coord.) Brazilian bauxites. USP/FAPESP/ORSTOM, Brazil. 55-73.

Costa M.L. 1991. Aspectos geológicos dos lateritos da Amazónia. Rev. Brás. Geoc., 21:146-160.

Dennen W.D. \& Norton H. A. 1977. Geology and geochemistry of bauxite deposits in the lower Amazon basin. Econ. Geol., 72:82-89.

Fernandes Filho L. A., Costa M.L., Costa J.B.S. 1996. Registros neotectônicos nos lateritos de Manaus. Geociências 16:9-33.

Góes A.M.O. \& Feujó F.J. 1994. Bacia do Parnaíba. Boletim de Geociências da Petrobrás, 8:57-67.

Grubb P.L.C. 1979. Génesis of bauxite deposits in the lower Amazon basin and Guiarias coastal plain. Econ. Geol., 74:735-750.

Hernalsteen C. M. de O. 1982. Bauxita de Porto Trombetas. In: Congresso Brasileiro de Geologia, 32., Salvador, 1982. Anais..., Salvador, SBG. vol 3, p. 1100-1114

Horbe A.M.C. \& Costa M.L. 1997. Solos gerados a partir do intemperismo de crostas lateríticas sílico-ferruginosas. Acta Amazônica 27:241-256.

Kotschoubey B. \& Truckenbrodt W. 1981. Evolução poligenética das bauxitas do distrito de Paragominas-Açailândia (estados do Pará e Maranhão). Rev. Bros. Geoc., 11:193-202.

Kotschoubey B., Truckenbrodt W, Heironimous B. 1997. Bauxite deposits of Paragominas. In: Carvalho A., Boulange B., Melfi A. J. \& Lucas Y. Brazilian bauxites, USP/FAPESP/ORSTOM, Brazil. 75-106.
Kronberg B.I, Couston J.F., Stílianidi Filho B., Fyfe W.S., Nash R.A., Sugden D. 1979. Minor element geochemistry of the Paragominas bauxite, Brazil. Econ. Geol, 74:1869-1875.

Kronberg B.I., Fife W.S., McKinnon B.J., Couston J.F., Stíllianidi Filho B, Nash R.A. 1982. Model for bauxite formation: Paragominas (Brazil). Chem. Geol., 35:311-320.

Lucas Y. 1988. Systemes pedologiques en amazonie brasilienses. Equilibres, desequilibres et transfprmations. Tese de doutorado, Université de Poitiers, Paris, $157 \mathrm{p}$.

Lucas Y. 1997. The bauxite of Juriti. In: Carcalho A., Boulange B., Melfi A.J., lucas Y. Brazilianbauxites, USP/FAPESP/ORSTOM, Brazil. 107-136.

Lucas Y., Luizão F.J., Chauvel A., Rouiller J., Nahon D. 1993. The relation between biológica! activity of the rain forest and mineral composition of soils. Science, 260:521-523.

Muller D., Bocquier G., Nahon D., Paquet H. 1980. Analyse des différenciatios mineralogiques et structurales d'un sol ferralli tique àhorizons nodulaires du Congo. Cah. ORSTOM, ser. Pedol., vol 18, p. 17-109.

Ruffet G., Innocent C., Michard A.. Féraud G Beauvais A., Nahon D., Hamelin B. 1996. A geochronological ${ }^{40} \mathrm{Ar} /{ }^{39} \mathrm{Ar}$ and ${ }^{87} \mathrm{Rb} /{ }^{87} \mathrm{Sr}$ study of $\mathrm{K}-\mathrm{Mn}$ oxides from the weathering sequence of Azul, Brazil. Geoch. et Cosmoch. Acta 60:2219-2232.

Tardy Y. 1993. Pétrologie des latentes et des sois tropicaux. Masson, Paris. 459 p.

Tardy Y. \& Roquin C. 1998. Derive dês continents Paléoclimats et altération tropicales. BRGM. 473 p.

Tardy Y., Trolard F., Roquin C., Novikoff A. 1990 Distribution of hydrated and dehidrated minerais in lateritic profijes and landscapes. In: Geochemistry of the earth's surface and mineral formation. 2 Intern. Symp. 133-136

Truckenbrodt W. \& Kotschoubey B. 1981. Cobertura terciária das bauxitas amazônicas. Rev. Brás. Geoc. 11:203-208.

Truckenbrodt W., Kotschoubey B., Góes A. M. 1982. Considerações a respeito da idade das bauxitas na pane leste da região Amazônica. In: Simpósio de Geologia da Amazónia, I, Belém, 1982, Anais... SBG, 1:201-209.

Truckenbrodt W., Kotschoubey B., Schellmann W. 1991. Composition and origin of the clay cover on north brazilian laterites. Geologische Rundschau, 80:591-610.

Vasconcelos P. M., Renne P.R., Brimhall G.H., Becker T.A. 1996. Direct dating of weathering phenomena by ${ }^{40} \mathrm{Ar} /{ }^{39} \mathrm{Ar}$ and $\mathrm{K}-\mathrm{Ar}$ analysis of supergene $\mathrm{K}-\mathrm{Mn}$ oxides. weathering phenomena by ${ }^{40} \mathrm{Ar} /{ }^{39} \mathrm{Ar}$ and

Wesselink L.G. 1990. Aluminum weathering in soil acidification modelling. Chemical Geology 94:150-152

Manuscrito A-1058
Recebido em 18 de novembro de 1998 Revisão dos autores em 24 de setembro de 1999 Revisão aceita em 25 de setembro de 1999 